\title{
EFEITO DO METRONIDAZOL NA MORFOLOGIA INTESTINAL E NA OCORRÊNCIA DE TRANSLOCAÇÃO BACTERIANA EM RATOS NA VIGÊNCIA OU NÃO DE OBSTRUÇÃO INTESTINAL
}

\author{
EFFECT OF METRONIDAZOL ON THE INTESTINAL MORPHOLOGY AND \\ OCCURRENCE OF BACTERIAL TRANSLOCATION IN RATS IN THE PRESENCE \\ OR ABSENCE OF INTESTINAL OBSTRUCTION
}

\author{
Adalberto Ferreira da Silva ${ }^{1}$ \\ José Eduardo de Aguilar-Nascimento, TCBC-MT ${ }^{2}$
}

\begin{abstract}
RESUMO: Objetivo: Translocação bacteriana (TB) é fenômeno associado a bactérias aeróbicas e, assim, drogas anaerobicidas poderiam favorecer a ocorrência deste fenômeno. Avaliar o efeito do metronidazol na morfologia intestinal e na ocorrência de TB na vigência ou não de obstrução intestinal. Método: Oitenta ratos Wistar foram randomizados para dois grupos: Metronidazol $(n=40)$ e Soro Fisiológico $(n=40)$. Cada grupo foi subdividido em quatro subgrupos de dez animais, denominados sem laparotomia, com laparotomia, com obstrução do íleo e com obstrução do sigmóide. Os animais receberam metronidazol ou soro fisiológico por $72 \mathrm{~h}$ sendo os procedimentos de cada subgrupo realizados após $48 \mathrm{~h}$ do início da medicação. Após a morte dos animais, os linfonodos mesentéricos, baço, fígado e sangue portal foram enviados para pesquisa de TB. Biópsias do jejuno, íleo e sigmóide foram avaliadas histomorfometricamente. Resultados: Houve maior mortalidade no grupo controle dentre os animais com obstrução intestinal. Não houve repercussões morfológicas com a utilização do metronidazol. A TB no grupo metronidazol $(8 / 40 ; 20 \%)$ foi maior que nos controles $(1 / 40 ; 2,5 \% ; \mathrm{p}=0.028)$ no subgrupo sem laparotomia. No subgrupo com obstrução ileal ocorreu mais translocação no grupo soro fisiológico quando comparado com o metronidazol $(27 / 40 ; 67,5 \%$ vs. $7 / 40 ; 17,5 \%$; p<0.001). Ocorreu mais translocação para linfonodos no grupo metronidazol com obstrução do sigmóide. Conclusões: Os achados sugerem que bactérias anaeróbicas protegem o organismo contra TB em ratos com trânsito intestinal preservado. Em animais com obstrução intestinal o local da obstrução influencia a translocação com uso do metronidazol. Na vigência de obstrução, o uso de metronidazol diminui a mortalidade dos animais.
\end{abstract}

Descritores : Translocação bacteriana; Metronidazol

\section{INTRODUÇÃO}

A translocação bacteriana tem sido o objeto de estudo em muitos trabalhos da literatura médica nos últimos anos. Wolochow et al. ${ }^{1}$ usaram o termo translocação bacteriana para designar a passagem de bactérias através da parede intestinal. Berg \& Garlington ${ }^{2}$ acrescentaram ao termo translocação bacteriana, a passagem de bactérias viá- veis da área gastrointestinal através da mucosa e lâmina própria para tecidos habitualmente estéreis, como linfonodos mesentéricos e outros órgãos. O termo tornou-se mais abrangente ao incluir a penetração de bactérias não viáveis e de produtos bacterianos como endotoxinas, partículas inertes, macromoléculas e fungos ${ }^{3,4}$.

Embora os mecanismos envolvidos na translocação bacteriana não sejam totalmente compreendidos, os mode-

1. Professor Auxiliar do Departamento de Cirurgia da FCM-UFMT

2. Professor Adjunto, Doutor em Medicina, do Departamento de Cirurgia da FCM-UFMT

Recebido em 12/9/2000

Aceito para publicação em 18/1/2001

Trabalho realizado no Departamento de Cirurgia da Faculdade de Ciências Médicas da Universidade Federal de Mato Grosso - FCM-UFMT. 
los experimentais sugerem a existência de pelo menos três fatores fisiopatológicos básicos: 1) comprometimento estrutural da barreira mucosa, 2) comprometimento do mecanismo imunológico e 3) comprometimento da microbiota nativa intestinal.

Denomina-se barreira intestinal, a capacidade do intestino de impedir que germens e substâncias potencialmente antigênicas, tóxicas ou carcinogênicas penetrem no organismo e alcancem o meio interno ${ }^{5}$. O mecanismo de defesa imunológico contra a translocação envolve um complexo sistema. A produção de IgA presente tanto na bile quanto nas secreções intestinais auxilia no reconhecimento de antígenos não apropriados para a absorção intestinal $^{6}$. O tecido linfóide associado ao intestino (sistema $G A L T$ ) formado por linfócitos, macrófagos, placas de Payer e linfonodos mesentéricos ${ }^{7}$ e o tecido linfóide difuso não agregado (sistema DLT) constituído por um grupo heterogêneo de células $\mathrm{B}, \mathrm{T}$, macrófagos, monócitos e um grande número de células plasmáticas são as partes mais importantes dessa defesa ${ }^{8}$. Apoiando todo esse sistema defensivo, agem as células de Kupffer, localizadas no fígado e no baço, atuando na captura de bactérias e neutralizando toxinas que, eventualmente, ultrapassem o epitélio intestinal e os linfonodos mesentéricos ${ }^{9}$.

O ecossistema da luz intestinal é também bastante importante na ocorrência de translocação bacteriana. ${ }^{10} \mathrm{~A}$ microbiota intestinal normal contém uma população estável de mais de 500 espécies de bactérias ${ }^{11}$. Essa população não só é estável, como também auxilia na prevenção de colonização da luz intestinal por bactérias patogênicas. Assim, vários trabalhos anteriores já demonstraram que o uso indiscriminado de antimicrobianos pode facilitar a proliferação e colonização intestinal de bactérias nocivas à saúde $^{12,13}$. Na fisiopatologia da translocação bacteriana, sabe-se que as bactérias aeróbicas Gram-negativas são as que mais translocam e que as bactérias anaeróbicas raramente o fazem, sendo competitivas com as primeiras e, talvez, por isso, possam exercer um papel benéfico na prevenção da translocação bacteriana.

Um dos medicamentos mais utilizados no combate de peritonites e em cirurgias colorretais para o tratamento das bactérias anaeróbicas é o metronidazol ${ }^{14}$. O precursor desse quimioterápico (o 5-nitroimidazol) foi descoberto por Nakamura apud Rollo ${ }^{15}$. Suas propriedades foram sendo descobertas após 1956, sendo inicialmente usado na clínica para tratamento da tricomoníase ${ }^{16}$.

Pode-se especular então que o uso de anaerobicidas possa exercer desequilíbrio no ecossistema intraluminal e favorecer a proliferação de bactérias aeróbicas Gram-negativas, predispondo a ocorrência de translocação bacteriana. A literatura nesse aspecto é pobre e trabalhos que investiguem essa hipótese seriam importantes.

Na obstrução intestinal, ocorre profunda alteração da microbiota intestinal, com crescimento e desequilíbrio da mesma, associado a importantes alterações da permeabilidade intestinal, e queda da capacidade de defesa imunológica ${ }^{17}$. Nesse contexto, vários trabalhos têm documentado um incremento da translocação na obstrução intestinal e, por isso, o modelo experimental de obstrução tem sido empregado para avaliar esse fenômeno.

Assim, o objetivo deste trabalho foi o de investigar experimentalmente o efeito do metronidazol na morfologia intestinal e na ocorrência de translocação bacteriana em ratos com ou sem obstrução intestinal.

\section{MÉTODOS}

O desenho do estudo foi submetido e aprovado pelo comitê de ética de pesquisa em animais do Instituto de Saúde Coletiva da Universidade Federal de Mato Grosso. Para responder ao objetivo deste trabalho foram constituídos de forma aleatória simples dois grupos de 40 ratos Wistar machos. O primeiro grupo recebeu o medicamento metronidazol (grupo metronidazol) e o segundo recebeu soro fisiológico (grupo-controle) por 72h. Cada grupo foi subdividido em quatro subgrupos de 10 animais, assim constituídos: subgrupo sem laparotomia, com laparotomia, com obstrução do íleo e, finalmente, subgrupo com obstrução do sigmóide. Após receberem por $48 \mathrm{~h}$ a medicação, foram praticados os procedimentos operatórios de laparotomia apenas (subgrupo laparotomia), laparotomia seguida de obstrução do íleo com náilon 4-0, $2 \mathrm{~cm}$ acima da válvula íleo cecal (subgrupo obstrução do íleo) e laparotomia seguida de obstrução do sigmóide com mesmo material $2 \mathrm{~cm}$ acima da reflexão peritoneal do reto (subgrupo obstrução do sigmóide). $\mathrm{O}$ fechamento da parede foi feito em todos os animais operados em dois planos com nylon 4-0. No quarto subgrupo não se praticou nenhuma intervenção (subgrupo sem laparotomia).

Após $72 \mathrm{~h}$ do início do experimento, em ambos os grupos, e nos diversos subgrupos, os animais foram mortos para retirada dos sítios extra-intestinais (fígado, baço e nódulos linfáticos mesentéricos), que após homogeneizados em câmara de fluxo laminar de ar, previamente esterilizada com raios ultravioleta por 30 minutos, eram inoculados em meio ágar Mac-Conkey, por 24-48h, e mantidos em estufa à $35^{\circ} \mathrm{C}^{18}$. O sangue portal foi colhido $(2 \mathrm{~mL})$ e imediatamente semeado em meio de cultura seletivo para Gram-negativos e Gram-positivos. Realizaram-se as provas bioquímicas para identificação da espécie bacteriana pela técnica de Rugai e Araújo modificada ${ }^{19}$. Biópsias do jejuno, íleo e sigmóide foram colhidas e lâminas contendo cortes sagitais foram coradas pela hematoxilina-eosina para avaliação morfológica. As variáveis consideradas neste estudo histológico foram as medidas da profundidade de cripta, espessura de parede, espessura do vilo e número de vilos $^{20}$. O estudo histomorfométrico foi realizado por um observador que desconhecia qualquer dado sobre o grupo ou subgrupo dos animais. Utilizou-se uma escala graduada, dividida em 100 unidades, adaptada à ocular do microscópio óptico com aumento de 100 vezes para as mensurações. Foi considerado como: a) profundidade de cripta - a distância da fosseta do vilo da mucosa até a lamina basal; b) espessura de parede - como sendo a distância da serosa à luz do intestino; c) espessura de vilo - a espessura no terço médio do vilo; d) número de vilos - foi obtido pela contagem do número de vilos no tamanho da escala 
graduada. Todas as medidas foram obtidas pela média aritmética de cinco medidas no segmento intestinal examinado, escolhendo-se sempre as glândulas melhor orientadas em cada corte.

Os animais do grupo metronidazol $(n=40)$ receberam metronidazol, na dosagem de $30 \mathrm{mg} / \mathrm{kg} / \mathrm{dia}$ no volume $0,3 \mathrm{~mL}$ por via intramuscular, de $12 / 12 \mathrm{~h}$ por $72 \mathrm{~h}$. Os animais do grupo soro fisiológico $(n=40)$, receberam solução de cloreto de sódio a $0,9 \%$ no volume também de $0,3 \mathrm{~mL}$ de $12 / 12 \mathrm{~h}$, por via intramuscular e pelo mesmo período.

Após o procedimento, os animais retornaram para suas gaiolas e foram mantidos com alimentação padrão e com água filtrada ad libitum. Os dados qualitativos foram acondicionados em tabelas $2 \times 2$ e analisados pelo teste do qui-quadrado ou exato de Fisher ${ }^{21}$. Para os dados quantitativos utilizou-se inicialmente o teste de Levene ${ }^{22}$ para testar a homogeneidade das amostras. Quando homogêneas, aplicou-se o teste t de Student. Caso contrário, utilizou-se o teste não paramétrico de Mann-Whitney ${ }^{22,23}$. Estabeleceu-se em 5\% (p < 0,05) o nível de significância estatística. Os resultados foram apresentados como média \pm desvio padrão ou mediana (variação) conforme o teste estatístico utilizado.

\section{RESULTADOS}

Foram utilizados 89 animais, sendo que nove morreram durante o experimento e, por isso, foram excluídos. Todos os que morreram pertenciam ao grupo soro fisiológico, sendo quatro animais do subgrupo obstrução do íleo e cinco animais do subgrupo obstrução do sigmóide. Não se observou óbito no grupo metronidazol.
Estatisticamente, essa diferença entre os dois grupos foi significante $(\mathrm{p}=0,003)$. A necropsia nesses animais não revelou sinais macroscópicos de peritonite ou de necrose de alça intestinal.

No estudo histológico, poucas diferenças foram observadas entre os dois grupos. Na avaliação morfológica do jejuno, não se observou diferença estatística quanto à profundidade de cripta entre os grupos metronidazol e soro fisiológico em nenhum dos subgrupos estudados. No subgrupo com obstrução do sigmóide, observou-se maior espessura da parede no grupo soro fisiológico quando comparado ao grupo metronidazol e, da mesma forma, no subgrupo com laparotomia, os vilos estavam mais espessos no grupo metronidazol com diferença estatística (Tabela 1).

Já no íleo, não se observou nenhuma diferença estatística entre os grupos metronidazol e soro fisiológico, em nenhuma variável histológica, com exceção do subgrupo obstrução do sigmóide, que apresentou um menor número de vilos no grupo metronidazol (Tabela 2).

No sigmóide não foram observadas diferenças significativas entre o grupo metronidazol e soro fisiológico em nenhuma das variáveis estudadas nos diversos subgrupos, conforme pode se ver na Tabela 3 .

$\mathrm{Na}$ Tabela 4, encontram-se os resultados da totalização das amostras de translocação bacteriana nos órgãos (baço, fígado, linfonodos e sangue) nos dois grupos e em cada subgrupo. No subgrupo sem laparotomia, observou-se apenas um caso $(2,5 \%)$ de translocação bacteriana no grupo soro fisiológico, enquanto ocorreram oito (20\%) casos no grupo metronidazol. Essa diferença foi estatisticamente significante $(\mathrm{p}=0,028)$. Já no subgrupo com laparotomia, não ocorreu diferença estatística. No subgrupo com obstrução do íleo,

Tabela 1

Média ( \pm DP) das variáveis profundidade da cripta, espessura de parede, espessura de vilo e números de vilos no jejuno nos subgrupos (sem laparotomia, com laparotomia, obstrução do íleo e do sigmóide) nos dois grupos (MTZ, SF)

\begin{tabular}{|c|c|c|c|c|c|c|c|c|}
\hline & \multicolumn{2}{|c|}{$\begin{array}{l}\text { Profundidade } \\
\quad \text { da cripta }\end{array}$} & \multicolumn{2}{|l|}{$\begin{array}{l}\text { Espessura } \\
\text { de parede }\end{array}$} & \multicolumn{2}{|l|}{$\begin{array}{l}\text { Espessura } \\
\text { de vilo }\end{array}$} & \multicolumn{2}{|l|}{$\begin{array}{l}\text { Número } \\
\text { de vilos }\end{array}$} \\
\hline & Média $\pm D P$ & $p$ & Média $\pm D P$ & $p$ & Média $\pm D P$ & $p$ & Média $\pm D P$ & $p$ \\
\hline \multicolumn{9}{|l|}{ Sem laparotomia } \\
\hline Metronidazol & $163,74 \pm 11,72$ & 0,33 & $541,85 \pm 89,62$ & $0,55 \#$ & $68,94 \pm 18,39$ & $0,14 \#$ & $9,1 \pm 2,0$ & 0,46 \\
\hline Soro fisiológico & $176,05 \pm 65,53$ & \# & $565,44 \pm 68,53$ & & $80,26 \pm 11,59$ & & $8,1 \pm 0,8$ & \#\# \\
\hline \multicolumn{9}{|l|}{ Com laparotomia } \\
\hline Metronidazol & $163,80 \pm 24,00$ & 0,11 & $611,51 \pm 99,85$ & $0,65 \#$ & $88,90 \pm 11,37 *$ & $0,01 * \#$ & $7,7 \pm 1,3$ & 0,21 \\
\hline Soro fisiológico & $148,32 \pm 16,54$ & \# & $631,77 \pm 97,89$ & & $71,14 \pm 16,71$ & & $8,8 \pm 2,4$ & \# \\
\hline \multicolumn{9}{|l|}{ Obstrução do íleo } \\
\hline Metronidazol & $133.36 \pm 35,95$ & 0,49 & $544,42 \pm 120,18$ & $0,20 \#$ & $68,63 \pm 14,83$ & $0,92 \#$ & $8,2 \pm 1,2$ & 0,66 \\
\hline Soro fisiológico & $122,41 \pm 27,29$ & \# & $475,211 \pm 85,59$ & & $68,24 \pm 15,76$ & & $9,3 \pm 2,4$ & \#\# \\
\hline \multicolumn{9}{|c|}{ Obstrução do sigmóide } \\
\hline Metronidazol & $142,87 \pm 30,80$ & $0,84 \#$ & $462,19 \pm 190,45$ & $0,04 * \#$ & $78,09 \pm 12,05$ & 0,16 \#\# & $8,0 \pm 1,3$ & 0,29 \\
\hline Soro fisiológico & $140,62 \pm 14,31$ & & $626,08 \pm 127,63^{*}$ & & $116,09 \pm 15,62$ & & $7,5 \pm 0,8$ & \#\# \\
\hline
\end{tabular}

$\#=$ teste $t$ Student

\#\# = Mann-Whitney 
Tabela 2

Média ( \pm DP) das variáveis profundidade da cripta, espessura de parede, espessura de vilo e números de vilos no íleo nos subgrupos (sem laparotomia, com laparotomia, obstrução do íleo e do sigmóide) nos dois grupos (MTZ, SF)

\begin{tabular}{|c|c|c|c|c|c|c|c|c|}
\hline & \multicolumn{2}{|c|}{$\begin{array}{l}\text { Profundidade } \\
\text { da cripta }\end{array}$} & \multicolumn{2}{|l|}{$\begin{array}{l}\text { Espessura } \\
\text { de parede }\end{array}$} & \multicolumn{2}{|l|}{$\begin{array}{l}\text { Espessura } \\
\text { de vilo }\end{array}$} & \multicolumn{2}{|l|}{$\begin{array}{l}\text { Número } \\
\text { de vilos }\end{array}$} \\
\hline & Média $\pm D P$ & $p$ & $M e ́ d i a \pm D P$ & $p$ & Média $\pm D P$ & $p$ & Média $\pm D P$ & $p$ \\
\hline \multicolumn{9}{|l|}{ Sem laparotomia } \\
\hline Metronidazol & $150,45 \pm 44,29$ & 0,42 & $377,70 \pm 51,87$ & $0,20 \#$ & $61,21 \pm 15,00$ & $0,83 \#$ & $10,7 \pm 3,1$ & 0,29 \\
\hline Soro fisiológico & $167,50 \pm 38,62$ & \# & $434,51 \pm 107,14$ & & $59,84 \pm 10,62$ & & $9,4 \pm 0,8$ & \# \\
\hline \multicolumn{9}{|l|}{ Com laparotomia } \\
\hline Metronidazol & $142,96 \pm 31,00$ & 0,17 & $381,76 \pm 108,30$ & $0,10 \#$ & $66,51 \pm 11,12$ & $0,44 \#$ & $9,6 \pm 1,0$ & 0,08 \\
\hline Soro fisiológico & $161,04 \pm 25,56$ & \# & $457,00 \pm 85,74$ & & $104,79 \pm 151,89$ & & $11,5 \pm 2,6$ & \#\# \\
\hline \multicolumn{9}{|l|}{ Obstrução do íleo } \\
\hline Metronidazol & $131,24 . \pm 39,58$ & 0,84 & $360,83 \pm 90,04$ & $0,51 \# \#$ & $65,54 \pm 12,64$ & $0,37 \#$ & $9,2 \pm 1,4$ & 0,33 \\
\hline Soro fisiológico & $122,26 \pm 23,57$ & \#\# & $327,92 \pm 42,29$ & & $69,84 \pm 6,71$ & & $8,5 \pm 1,6$ & \# \\
\hline \multicolumn{9}{|c|}{ Obstrução do sigmóide } \\
\hline Metronidazol & $153,07 \pm 33,32$ & 0,92 & $472,07 \pm 94,58$ & $0,64 \#$ & $66,37 \pm 12,35$ & $0,44 \#$ & $8,1 \pm 1,0$ & $0,04 *$ \\
\hline Soro fisiológico & $150,94 \pm 51,621$ & \# & $444,35 \pm 136,61$ & & $111,23 \pm 159,23$ & & $10,8 \pm 2,1^{*}$ & \#\# \\
\hline
\end{tabular}

\# = teste $t$ Student

\#\# = Mann-Whitney

Tabela 3

Média ( \pm DP) das variáveis profundidade da cripta, espessura de parede, espessura de vilo e números de vilos no sigmóide nos subgrupos (sem laparotomia, com laparotomia, obstrução do íleo e do sigmóide) nos dois grupos (MTZ, SF)

\begin{tabular}{|c|c|c|c|c|c|c|c|c|}
\hline & \multicolumn{2}{|c|}{$\begin{array}{l}\text { Profundidade } \\
\text { da cripta }\end{array}$} & \multicolumn{2}{|l|}{$\begin{array}{l}\text { Espessura } \\
\text { de parede }\end{array}$} & \multicolumn{2}{|l|}{$\begin{array}{l}\text { Espessura } \\
\text { de vilo }\end{array}$} & \multicolumn{2}{|l|}{$\begin{array}{l}\text { Número } \\
\text { de vilos }\end{array}$} \\
\hline & Média $\pm D P$ & $p$ & Média $\pm D P$ & $p$ & Média $\pm D P$ & $p$ & Média $\pm D P$ & $p$ \\
\hline \multicolumn{9}{|l|}{ Sem laparotomia } \\
\hline Metronidazol & $239,17 \pm 26,22$ & 0,21 & $412,54 \pm 26,21$ & $0,11 \#$ & $50,22 \pm 8,35$ & $0,41 \#$ & $12,3 \pm 2,4$ & 0,28 \\
\hline Soro fisiológico & $220,65 \pm 30,14$ & \# & $382,09 \pm 43,66$ & & $47,08 \pm 6,23$ & & $13,5 \pm 2,0$ & $\#$ \\
\hline \multicolumn{9}{|l|}{ Com laparotomia } \\
\hline Metronidazol & $245,80 \pm 29,38$ & 0,75 & $446,21 \pm 66,10$ & $0,40 \#$ & $39,51 \pm 4,58$ & $0,44 \#$ & $16,3 \pm 2,1$ & 0,31 \\
\hline Soro fisiológico & $239,72 \pm 48,98$ & \# & $466,89 \pm 47,34$ & & $41,01 \pm 3,55$ & & $17,4 \pm 2,2$ & $\#$ \\
\hline \multicolumn{9}{|l|}{ Obstrução do íleo } \\
\hline Metronidazol & $211,84 \pm 44,53$ & 0,29 & $439,76 \pm 73,38$ & $0,45 \#$ & $36,74 \pm 4,47$ & $0,08 \#$ & ${ }^{17}, 3 \pm 2,4$ & 0,26 \\
\hline Soro fisiológico & $239,17 \pm 62,43$ & \# & $501,78 \pm 240,05$ & & $40,80 \pm 4,90$ & & $16,1 \pm 2,0$ & \# \\
\hline \multicolumn{9}{|c|}{ Obstrução do sigmóide } \\
\hline Metronidazol & $256,71 \pm 64,54$ & 0,62 & $537,52 \pm 175,96$ & $0,84 \#$ & $47,29 \pm 11,59$ & $0,72 \#$ & $15,6 \pm 2,7$ & 0,19 \\
\hline Soro fisiológico & $242,98 \pm 57,52$ & \# & $552,92 \pm 164,13$ & & $42,01 \pm 2,29$ & & $17,1 \pm 2,9$ & \#\# \\
\hline
\end{tabular}

$\#=$ teste $t$ Student

\#\# = Mann-Whitney

verificou-se a presença de translocação bacteriana em 27 $(67,5 \%)$ amostras na vigência do soro fisiológico e em sete $(17,5 \%)$ amostras na vigência do medicamento metronidazol ( $\mathrm{p}<0,001)$. No entanto, no subgrupo com obstrução do sigmóide, ocorreu translocação bacteriana em 22 amostras (55\%) na vigência do uso de metronidazol, e, somente, em 16 amostras $(40 \%)$ no grupo soro fisiológico $(\mathrm{p}>0,05)$.
Contudo, quando se compararam apenas os dados de translocação bacteriana para os linfonodos, observou-se que a ocorrência de translocação bacteriana nesse último subgrupo foi significantemente maior nos ratos que receberam tratamento com metronidazol (Tabela 5).

Comparando-se a TB nos subgrupos sem laparotomia e com laparotomia na vigência do uso de soro fisioló- 
Tabela 4

Totalização da ocorrência de translocação bacteriana entre grupos em cada subgrupo

\begin{tabular}{|c|c|c|c|c|c|}
\hline & \multicolumn{5}{|c|}{ Translocação } \\
\hline & Sim & $\%$ & Não & Total & $p$ \\
\hline \multicolumn{6}{|l|}{ Sem laparotomia } \\
\hline Metronidazol & $8 *$ & $(20,0)$ & 32 & 40 & $0,028 * \# \#$ \\
\hline Soro fisiológico & 1 & $(2,5)$ & 39 & 40 & \\
\hline \multicolumn{6}{|l|}{ Com laparotomia } \\
\hline Metronidazol & 7 & $(17,5)$ & 33 & 40 & $0,51 \#$ \\
\hline Soro fisiológico & 4 & $(10,0)$ & 36 & 40 & \\
\hline \multicolumn{6}{|l|}{ Obstrução do íleo } \\
\hline Metronidazol & 7 & $(17,5)$ & 33 & 40 & $0,001 * \#$ \\
\hline Soro fisiológico & $27 *$ & $(67,5)$ & 13 & 40 & \\
\hline \multicolumn{6}{|c|}{ Obstrução do sigmóide } \\
\hline Metronidazol & 22 & $(55,0)$ & 18 & 55,0 & $0,26 \#$ \\
\hline Soro fisiológico & 16 & $(40,0)$ & 24 & 40,0 & \\
\hline
\end{tabular}

Teste $c^{2}=\#$

Teste exato de Fisher $=$ \#\#

Tabela 5

Translocação bacteriana para os linfonodos nos dois grupos de animais com obstrução do sigmóide

\begin{tabular}{l|cc|c|c}
\hline \multirow{2}{*}{ Grupo } & \multicolumn{2}{|c|}{ Translocação } & & \\
\cline { 2 - 3 } & Sim & Não & Sim (\%) & Total \\
\hline Metronidazol & $8^{*}$ & 2 & 80 & 10 \\
Soro fisiológico & 3 & 7 & 30 & 10 \\
\hline Total & 11 & 9 & 55 & 20 \\
\hline
\end{tabular}

Teste exato de Fisher $p=0,03 *$

gico, verificou-se que não houve diferença estatística $(\mathrm{p}=0,36)$. Já na comparação dos subgrupos sem laparotomia e obstrução do íleo, sem laparotomia e obstrução do sigmóide, obstrução do íleo e obstrução do sigmóide, laparotomia e obstrução do íleo e, finalmente, laparotomia e obstrução do sigmóide, o estudo mostrou significância estatística com maior incidência de translocação bacteriana nos grupos com obstrução e, dentre eles, com maior intensidade no grupo com obstrução do íleo (Tabela 6).

Já no grupo metronidazol, comparando-se os subgrupos sem laparotomia e com laparotomia; sem laparotomia e obstrução do íleo; laparotomia e obstrução do íleo, não houve diferença estatística entre eles quanto à presença de TB. No entanto, na comparação entre os subgrupos sem laparotomia e obstrução do sigmóide, com laparotomia e obstrução do sigmóide, e, finalmente, obstrução do íleo com obstrução do sigmóide, existiu diferença estatística, conforme demonstrado na Tabela 6.

\section{DISCUSSÃO}

O conjunto dos resultados do estudo histológico, infere que o metronidazol não determina alterações importantes à luz do microscópio ótico comum na barreira mucosa, em qualquer uma das situações estudadas. Isto é particularmente importante na medida em que a translocação bacteriana é dependente do comprometimento intestinal da barreira mucosa, do estado imunológico do indivíduo e, finalmente, da microbiota existente na luz intestinal ${ }^{7}$. Assim, esses achados diminuem a possibilidade da ocorrência de translocação ligada ao metronidazol ser de fruto alterações estruturais da barreira mucosa.

O presente experimento deixou de realizar a cultura de bactérias anaeróbicas. Importante para documentar a colonização intestinal por estes germes, com ou sem metronidazol, e, ainda, nos diferentes tipos de obstrução. Embora isso fosse importante, o estudo incorporou a pressuposta ação anaerobicida do metronidazol já descrita e bem documentada na literatura ${ }^{10,33}$.

A ocorrência de translocação bacteriana em situação de normalidade tem sido descrita numa freqüência de 5\%, tanto em animais quanto em seres humanos, sem contudo esse fenômeno levar à infecção ou à disfunção de múltiplos órgãos $2,24,27,28,31,34$. Isso ocorreu em 2,5\% dos animais controles neste experimento. Acredita-se que a translocação bacteriana possa ser fisiológica, sendo importante a entrada de uma pequena quantidade de bactérias ou endotoxinas pela barreira intestinal para sensibilizar o organismo nos mecanismos de defesa ${ }^{25}$.

O uso do metronidazol nos ratos em condições basais foi significantemente associado à ocorrência de trans- 
Tabela 6

Totalização da ocorrência de translocação bacteriana entre subgrupos em cada grupo

\begin{tabular}{|c|c|c|c|c|c|c|}
\hline & & \multicolumn{5}{|c|}{ Translocação } \\
\hline & & Sim & $\%$ & Não & Total & $p$ \\
\hline \multirow[t]{12}{*}{ Soro fisiológico } & Sem laparotomia & 1 & $(2,5)$ & 39 & 40 & $0,36 \#$ \\
\hline & Com laparotomia & 4 & $(10,0)$ & 36 & 40 & \\
\hline & Sem laparotomia & 1 & $(2,5)$ & 39 & 40 & $0,001 * \#$ \\
\hline & Obstrução do íleo & $27 *$ & $(67,5)$ & 13 & 40 & \\
\hline & Sem laparotomia & 1 & $(2,5)$ & 39 & 40 & $0,001 * \#$ \\
\hline & Obstrução do sigmóide & $16^{*}$ & $(40,0)$ & 24 & 40 & \\
\hline & Laparíumia & 4 & $(10,0)$ & 36 & 40 & $0,001 * \#$ \\
\hline & Obstrução do íleo & $27 *$ & $(67,5 \%)$ & 13 & 40 & \\
\hline & Laparíumia & 4 & $(10,0)$ & 36 & 40 & $0,002 * \#$ \\
\hline & Obstrução do sigmóide & $16^{*}$ & $(40,0)$ & 24 & 40 & \\
\hline & Obstrução do íleo & $27 *$ & $(67,5)$ & 13 & 40 & $0,014 * \#$ \\
\hline & Obstrução do sigmóide & 16 & $(40,0)$ & 24 & 40 & \\
\hline \multirow[t]{12}{*}{ Metronidazol } & Sem laparotomia & 8 & $(20,0)$ & 32 & 40 & $1,00 \#$ \\
\hline & Com laparotomia & 7 & $(17,5)$ & 33 & 40 & \\
\hline & Sem laparotomia & 8 & $(20,0)$ & 32 & 40 & $0,78 \#$ \\
\hline & Obstrução do íleo & 7 & $(17,5)$ & 33 & 40 & \\
\hline & Sem laparotomia & 8 & $(20,0)$ & 32 & 40 & $0,001 * \#$ \\
\hline & Obstrução do sigmóide & $22 *$ & $(55,0)$ & 18 & 40 & \\
\hline & Laparotomia & 7 & $(17,5)$ & 33 & 40 & $1,00 \#$ \\
\hline & Obstrução do íleo & 7 & $(17,5)$ & 33 & 40 & \\
\hline & Laparotomia & 7 & $(17,5)$ & 33 & 40 & $0,001 * \#$ \\
\hline & Obstrução do sigmóide & $22 *$ & $(55,0)$ & 18 & 40 & \\
\hline & Obstrução do íleo & 7 & $(17,5)$ & 33 & 40 & $0,001 * \#$ \\
\hline & Obstrução do sigmóide & $22^{*}$ & $(55,0)$ & 18 & 40 & \\
\hline
\end{tabular}

Teste $\chi^{2}=\#$

Teste exato de Fisher = \#\#

locação bacteriana. Embora em cada órgão isolado os percentuais verificados não tenham atingido a significância estatística (dados não apresentados), a totalização de casos de translocação bacteriana foi maior com o uso deste quimioterápico. Esse aumento na ocorrência de translocação bacteriana pode ser explicado pela ação antimicrobiana seletiva do metronidazol para germens anaeróbicos ${ }^{12,29}$. A quebra do microssistema ecológico da luz intestinal, favorável ao crescimento dos germens aeróbicos sem a competição dos anaeróbicos, foi, com muita possibilidade, a causa deste resultado. Estes resultados pressupõem então que o uso indiscriminado de anaerobicidas em condições basais pode promover a translocação bacteriana.

Os resultados observados nos animais laparotomizados, também mostraram, embora não significativamente, um maior percentual de casos de translocação bacteriana no grupo metronidazol. Contudo, houve aumento também nos animais de controle. Provavelmente, a associação do trauma operatório e sua conseqüente reação inflamatória sistêmica determinaram alterações fisiológicas da barreira mucosa com acréscimo da permeabilidade ${ }^{5,7}$, aumentando, assim, os casos de translocação bacteriana nos dois grupos. Nessa nova situação então, onde o trauma também atuou como indutor da translocação, a ação sinérgica do metronidazol não foi sensível ao teste estatístico.

A obstrução intestinal, definitivamente, tanto em condições experimentais ${ }^{17,27,28,32}$ quanto em condições clínicas $^{24,26,29-31}$, está associada à translocação bacteriana. As razões para isso vão desde o aumento da permeabilidade da barreira mucosa ao crescimento bacteriano na luz intestinal $^{31}$. Neste estudo, incluíram-se dois subgrupos, um com obstrução em nível do íleo terminal e outro com obstrução em nível do sigmóide para se estudar a ocorrência de translocação bacteriana nestas duas situações extremas e, tam- 
bém, qual influência a utilização de um anaerobicida poderia acarretar. Os resultados mostraram que na obstrução do íleo terminal nos ratos em uso de soro fisiológico, a incidência de translocação foi maior quando comparada à verificada em condições normais. Estes achados são semelhantes aos que diversos outros autores já reportaram anteriormente ${ }^{31}$. Entretanto, nos animais que receberam o metronidazol, a taxa de translocação bacteriana foi significantemente menor, que a observada no grupo soro fisiológico. Isto parece significar que, nesta situação de urgência, o valor da ação antimicrobiana, embora voltada apenas para os anaeróbicos, foi importante para minimizar o fenômeno da translocação. Isso também poderia explicar o menor número de óbitos nesse grupo. Na verdade, o que se observa em termos numéricos e percentuais na obstrução do íleo é que, enquanto a taxa de translocação bacteriana aumenta nos animais do grupo soro fisiológico, ela não se modifica nos animais do grupo metronidazol. Em outras palavras, enquanto que nos animais do soro fisiológico a ocorrência de translocação bacteriana aumenta significantemente indo de uma taxa baixíssima $(2,5 \%)$ para uma taxa elevadíssima $(67,5 \%)$ na vigência de obstrução do íleo, nos animais tratados com metronidazol ela que já é alta em condições basais (20\%) não se modifica com o acréscimo da obstrução do íleo terminal $(17,5 \%)$.

Da mesma maneira, a incidência de translocação bacteriana aumentou nos ratos com obstrução do sigmóide, quando comparados aos estudados em condições basais. Assim, esta taxa que foi de 2,5\% nos animais do grupo soro fisiológico sem laparotomia aumentou para $40 \%$ quando submetidos à obstrução do sigmóide. Nos animais que receberam metronidazol esse aumento de casos de translocação bacteriana também ocorreu, indo de $20 \%$ dos casos sem laparotomia para $55 \%$ nos casos de obstrução. Entretanto, a análise comparativa entre os dois grupos não mostrou diferença significativa entre eles. Isto se deveu, em parte, ao grande aumento da taxa de translocação bacteriana dos animais grupo soro fisiológico. Contudo, nos linfonodos mesentéricos houve mais translocação com uso de metronidazol. Este achado está em consonância com a hipótese de que a diminuição da microbiota anaeróbica pelo metronidazol tenha ocasionado um aumento dos aeróbios Gram-negativos. Tendo em vista que, segundo a literatura, os Gram-negativos são as bactérias que mais translocam ${ }^{12,28,33}$, a redução da microbiota anaeróbica que compete com essas bactérias, talvez tenha sido a responsável por esse aumento de translocação bacteriana.

Em conclusão, os achados suportam a hipótese de que bactérias anaeróbicas protegem o organismo contra translocação bacteriana em situação de normalidade, competindo com bactérias facultativas aeróbicas, com equilíbrio da flora intestinal. No entanto, nos casos de obstrução, o uso de metronidazol diminuiu a mortalidade. O local de obstrução parece influenciar na ocorrência de maior ou menor translocação associada ao metronidazol. Enquanto que na obstrução do íleo diminui com o uso deste quimioterápico, na obstrução do sigmóide, pelo menos para os linfonodos, ela aumenta.

\begin{abstract}
Background: Aerobic flora is associated with bacterial translocation (BT). The anaerobic flora may have a role in the occurrence of this phenomenon. The aim of this study was to investigate the effect of metronidazol on the intestinal morphology and on the occurrence of BT in the presence or absence of intestinal obstruction. Methods: Eighty wistar rats were randomized to two groups: group metronidazol $(n=40)$ and group saline $(n=40)$. They received the correspondent medication for $72 \mathrm{~h}$. Each group comprised four subgroups of 10 rats each as follows: without laparotomy, with laparotomy, ileal and sigmoideal obstruction. After receiving the solutions for 48h, the rats underwent different operative procedures depending on the subgroups except for subgroup without laparotomy in which no operation was carried out. They were killed after $72 \mathrm{~h}$ and the mesenteric lymph nodes, liver, spleen and blood samples were cultured. Biopsies of the jejunum, ileum and sigmoide were collected and sent to histomorphometric measurements. Results: A significantly higher mortality was observed in group saline in obstructed animals. There was no important morphological differences between the groups. In metronidazol group the incidence of BT $(8 / 40 ; 20 \%)$ was significantly higher $(p=0.028)$ than in controls $(1 / 40 ; 2,5 \%)$ in nonoperated animals. In the subset of ileum obstruction, the rate of BT was higher in controls than in metronidazol group $(27 / 40 ; 67,5 \%$ vs. $7 / 40 ; 17,5 \%$; 10.001$)$. However, there was greater translocation to lymph nodes in metronidazol group compared with controls in sigmoid obstructed rats. Conclusions: Metronidazol favors the occurrence of BT under basal conditions. There is no important morphological alteration induced by metronidazol. Intestinal obstruction enhances BT and the site of obstruction influences the rate of translocation associated with metronidazol. However, mortality is lower when metronidazol is used in obstructed animals.
\end{abstract}

Key Words: Bacterial translocation; Metronidazol. 


\section{REFERÊNCIAS}

1. Wolochow H, Hildebrand G, Lammanna C - Translocation of microorganisms across the intestinal wall of the rat: effect of microbial size and concentration. J Infect Dis 1966 ; 116:523-8.

2. Berg RD, Garlington AW - Translocation of certain indigenous bacteria from the gastrointestinal tract to the mesenteric lymph nodes and other organs in a antibiotic mouse model. Infect Immun 1979; 23:403-11.

3. Alexander JW - Nutrition and translocation. JPEN 1990; $14: 170-4$

4. Alexander JW, Boyce ST, Babcock GF, et al - The process of microbial translocation. Ann Surg 1990; 212:496510.

5. Hollander D - The intestinal permeability barrier. Gastroenterology 1992; 27:721-6.

6. Alverdy JC, Hoon SC, Selvanov V, et al - The effect of route nutrient administration on the secretory system.Cur Surg 1985; 12: 10-3.

7. Swank GM, Deitch EA - Role of the gut in multiple organ failure: bacterial translocation and permeability changes. World J Surg 1996; 20: 411-7.

8. Martinez JC - The gut: its role in the critical patient and the concept of bacterial translocation. Rev. Méd Chile 1993; 121: 800-10.

9. Stechmiller JK, Treloar D, Allen N - Gut dysfunction in critcally ill patients; a review of the literature. Am J Crit Care 1997; 6:204-9.

10. Wells CL, Maddaus AM, Reynolds CM, et al - Role of the macrophage in the translocation of intestinal bacteria. Arch Surg 1987; 122:48-53

11. Moore WEC, Holdeman LV - Some newer concepts of the human intestinal flora AJMT 1975; 79:427-30.

12. Berg RD - Promotion of the translocation of enteric bacteria from the gastrointestinal tracts of mice by oral treatment with penicilin, clindamycin, or metronidazol. Infect Immun 1981; 33:854-61.

13. Hentges DJ, Stein AJ, Casey SW, et al - Protective role of intestinal flora against infection with Pseudomonas aeruginosa in mice: influence of antibiotics on colonization resistance. Infect Immun 1985; 47:118-22.

14. Finegold SM - Therapy for infections due to anaerobic bacteria: an overview. J Infec Dis 1977; 135:25-9.

15. Rollo IA - Combinação de medicamentos usados no tratamento de infecções por protozoários. In Gilman, A.G.; Goodman, L S.; Gilman, A . - As Bases Farmacológicas da Terapêutica. Rio de Janeiro - RJ, Guanabara Koogan 1983 pp 937-5.

16. Strans MH, Bradley WE: Metronidazole. Drug Intell Clin Pharm 1981; 15:838-46.

17. Akçay MN, Çapan MY, Gundogdu G, et al - Bacterial translocation in experimental intestinal obstruction. J Int Med Res 1996; 24:17-26.

18. Burns MC, Richter ER, Rhenis MS - An identification scheme for gram-negative fermentative and nonfermentative bacteria. Public Health Lab 1982; 40:87-108.

19. Pessoa GVA, Silva EAM - Milieu pour l'identification présomptive rapide des enterobactéries, des aeromonas et des vibrions. Ann Microbiol 1974; 125:341-7.

20. Aguilar-Nascimento JE, Lima AS, Pereira ACC - Effects of oral parenteral nutrition on the morphology and mechanical resistence of the small bowel in rats. Acta Cir Bras 1997; 12:159-62.
21. Sigel S - Nonparametric statistics. Mc Gran-Hill. New York, 1956.

22. Olkin I - Contributions to probability and statistics. Standford University Press. Palo Alto 1960.

23. Kinear PR, Gray CD - SPSS for Windows, $1^{\text {a }}$ Ed., Psichology Press UK 1994

24. Macfie $\mathbf{J}$ - Bacterial translocation in surgical patients. Ann R Coll Surg Engl 1997; 79:183-9.

25. Van-Leeuwen PAM, Boermeester MA, Houdijk APJ, et al Clinical significance of translocation. Gut 1994; 35:S28-34.

26. Deitch EA - Simple intestinal obstruction causes bacterial translocation in man Arch Surg 1989; 124:699-701.

27. Wells CL - Relationship between intestinal microecology and the translocation of intestinal bacteria. Antonie Van Leeuwenhoek 1990; 58: 87-93.

28. Aguilar-Nascimento JE, Garcia A, Silva-Junior, PPR, et al Translocação bacteriana na obstrução aguda do cólon esquerdo. Rev Bras Colo-Proct 2000; 20:19-22.

29. Sedman PC, Macfie J, Sagar P, et al - The prevalence of gut translocation in humans. Gastroenterology 1994; 107:643-9.

30. Sagar PM, FRCS, Macfie J, Sedman P, et al - Intestinal obstruction gut translocation of bacteria. Dis Colon Rectum 1995 ; 38:640-4

31. Deitch EA, Bridges, MW, Ma WJ, et al - Obstructed intestine as a reservoir for systemic infection. Am J Surg 1990; 159:394-401.

32. Marshall JC, Christou NV, Meakins JL - The gastrointestinal tract: the "undrained abscess" of multiple organ failure. Ann Surg 1993; 2:111-9.

33. Rigatto $\mathrm{M}$ - O papel dos antibióticos na medicina contemporânea. In Penildon, S. Farmacologia. Rio de Janeiro, Guanabara Koogan; 1988; pp 944-7.

34. Nieuwenhuijzen GAP, Deitch EA, Goris JÁ - The relationship between gut derived bacteria and the development of the multriple organ dysfunction syndrome. J Anat 1996;189:537-48.

Endereço para correspondência:

Dr. Adalberto Ferreira da Silva

Rua Sírio Libaneza, 60/801

78045-710 - Cuiabá - MT

Tel: (65) 623-5238 